This is the version of the chapter accepted for publication in Cultural Contestation in China: Ethnicity, Identity and the State published by Palgrave Macmillan https://doi.org/10.1007/978-3-319-91914-0

Accepted version downloaded from SOAS Research Online: http://eprints.soas.ac.uk/31090/

\title{
Cultural Contestation in China: Ethnicity, Identity and the State
}

\author{
Christina Maags
}

\section{Introduction}

During the past two decades, the protection of traditional cultural practices has taken center stage in international cultural governance. With the adoption of the UNESCO Convention for the Safeguarding of Intangible Cultural Heritage (ICH Convention) in 2003, 171 state parties have committed to implementing domestic "intangible cultural heritage" (ICH) safeguarding measures. ICH refers to "practices, representations, expressions, knowledge, skills - as well as the instruments, objects, artefacts and cultural spaces associated therewith - that communities, groups and, in some cases, individuals recognize as part of their cultural heritage" (UNESCO 2003). Among the earliest signatories is the People's Republic of China (PRC), which has eagerly implemented various UNESCO "best practices" of $\mathrm{ICH}$ safeguarding. This is surprising as the PRC previously banned many forms of traditional culture - most notably during the Cultural Revolution. Among the UNESCO's best practices, the PRC adopted a national inventory of $\mathrm{ICH}$ practices, creating $\mathrm{ICH}$ lists on multiple government levels, as well as its own variation of the Living Human Treasures System (UNESCO 2002), the ICH Inheritor program (chuanchengren xiangmu) (SC 2005; MOC 2006).

Although the PRC's official embrace of traditional culture has unleashed an "ICH fever" among the Chinese populace, enhancing awareness and promotion (Maags 2018 forthcoming), the party-state's ICH safeguarding programs have not only had positive effects. Indeed, the listing of $\mathrm{ICH}$ practices on domestic and UNESCO $\mathrm{ICH}$ representative lists as well as the $\mathrm{ICH}$ inheritor program has created exclusion and inclusion effects which have fueled cultural contestation among local communities (Svensson 2006; Maags 2018 forthcoming). Although heritage lists' exclusion and inclusion effects have been welldocumented (Hafstein 2009: 104), few studies examine how administrative implementation mechanisms intentionally and unintentionally create these effects. This is surprising as academic literature identifies state policy and bureaucracy as a major cause for cultural contestation (e.g. Harrison 2010; Waterton 2010). 
Cultural contestation arises between two distinct ethnic or cultural groups, or between the state and such groups. While much as been written about the interests and strategies behind engaging in contestation, Ross (2007) has emphasized that cultural contestation goes beyond these structural or interest-based approaches. In fact, what matters are the groups' identities which are strongly connected to heritage, cultural practices and expressions be they tangible such as landscapes, monuments and artefacts or intangible as for instance rituals, festivals or language. To capture the role cultural identity plays in cultural contestation, Ross therefore agues for examining cultural expressions as markers of identity and to retrace changes in cultural narratives which may either be exclusive, thus enhancing the conflict, or inclusive, providing an opportunity to mitigate further conflicts (2007: 1-3).

Following Ross' call for a greater focus on cultural identity and expressions in political science research on cultural contestation, this chapter inquires into the ways government policy and administrative procedures foster cultural contestation between the state and ethnic groups. It seeks to add to the literature by shedding light on the multiple and often ambiguous effects government policy and administration may have on local ethnic culture due to its multi-level structure. It also seeks to show how these effects do not necessarily result in open contestation and conflict, but also take more indirect or subtle forms of resistance. Drawing on a case study of Lancang County in Yunnan province, PR China, this chapter will demonstrate the ways in which the different interests and strategies within Chinese multi-level governance may on the one hand promote ethnic cultural identities and vernacular practices, while simultaneously brushing over them to pursue economic and political interests on the other, thereby creating local cultural contestation.

The chapter is structured as follows: After providing a review of the scholarly literature on this topic, I will briefly introduce the theoretical and methodological approach which inform this study. The main part of the chapter will demonstrate, firstly, how Chinese change in policy and administration have provided opportunities for Lancang County to foster its cultural identity and receive national recognition for its cultural practices. Subsequently, the chapter will outline how diverging interests within Chinese multi-level governance result in local, indirect forms of cultural contestation through the establishment of counternarratives. After a discussion on the ambiguous effects of the Chinese multi-level governance on local community culture, this chapter will end with some concluding remarks on the broader issues underlying ethnic identity and cultural contestations in "state-nations"1 of the Global South.

\footnotetext{
${ }^{1}$ Stepan et al. (2010) have argued that state nations are "multicultural, and sometimes even have significant multinational components, which nonetheless still manage to engender strong identification and loyalty from their citizens, an identification and loyalty that proponents of homogeneous nation states perceive that only nation states can engender" (2010: 4). In contrast to nation-states, state-nations, however, are "robustly multinational" societies as the states "have deep cultural diversity, some of which is territorially based and politically articulated
} 


\section{The State of the Art}

A study of the PRC nicely reflects broader issues around ethnicity, cultural identity and the state unfolding in many post-colonial or post-communist states. Like many other countries, the Chinese state has undergone many ruptures in its development, particularly in the cultural realm. As mentioned above, while the Chinese party-state had criticized traditional culture and religion as superstitious and feudal, resulting in a large-scale repression and destruction of it tangible and intangible heritage during the Cultural Revolution (Gao Yuan 1987: 85-95), it has slowly changed its attitude since its Reform and Opening Period commenced in 1978 (Barmé 1999: 236; 256). This change in attitude has triggered heightened scholarly interest in the reasons and implications of this change in government policy. Blumenfield and Silverman (2013), for instance, have argued that the Chinese partystate has renewed interest in its past as it may be used as a tool to promote nationalist sentiments among the populace, enhance economic development as well as legitimize minority politics (2013: 3-23). Many academic studies have examined the use of heritage as resource to develop the tourism industry (Shepherd and Yu 2012; Zhu and Li 2013), to enhance nationalism (Gladney 1996; Cheung 2012) and foster ethnic minority relations (Yang et al. 2008; Zhu 2016) whereas others have studied underlying governmental policies and procedures (Bodolec 2012; Liang 2013; Maags and Holbig 2016).

Studying the impact on government policies on local communities, many scholars have demonstrated that government policies and procedures foster cultural contestation between the Chinese state and local communities (Schein 2000; Svensson 2006; Yu 2015). You (2015), for instance, has pointed to the conflicts that emerge between different state and local actors during the negation of which $\mathrm{ICH}$ practices are to be nominated for inclusion on $\mathrm{ICH}$ lists. She shows that conflicts not only arise due to cultural contestation between local communities concerning whose traditions are to be officially recognized. Conflicts also occur due to the lack of non-state actor involvement in decision-making as local governments control the inscription process, its management as well as the allocation of state funds. In a similar vein, Chen (2015) has examined local government's interest in using ICH as a tourism resource and argues that the subjectivity and agency of local cultural practitioners are constrained and weakened through strong state control.

As the People's Republic is home to 56 ethnic minorities (Wang 2015: 4), state control and resulting cultural contestation are at times exacerbated in ethnic minority areas. Echoing Chau's (2005) claim that the party-state seeks to de-politicise religion by reframing it as culture, Liang (2013) has examined how the local government in Dali Bai Autonomous

by significant groups that, in the name of nationalism and self-determination, advance claims of independence" (Stepan et al. 2010: 1-4). 
Prefecture in Yunnan province has gone to great efforts to inscribe a local religious festival on the domestic ICH items list, particularly associating a supposed fertility cult and sexual promiscuity with the festival. ${ }^{2}$ Yet the party-state's control of $\mathrm{ICH}$ inscription and management is also resisted by local non-state stakeholders. In her analysis of Miao village ritual practices $\mathrm{Yu}$ (2015) has found that local communities create and disseminate counternarratives as well as secretly and publicly perform their rituals which go against official interpretations of the $\mathrm{ICH}$ practice.

In PR China, cultural contestation between the state and ethnic groups are thus commonly related to the party-state's desire to control and depoliticize ethnic minority culture and religion on the one hand, while making economic profit on the other. As the examples of cultural contestation and resistance have shown, in an authoritarian state such as China ethnic groups rarely openly contest state policies producing cultural contestations, and rather use alternative more subtle ways of resisting cultural "superscription" (cf. Duara 2010). Moreover, many studies are couched in a narrative of "the state" vs. "the ethnic minority" - a narrative which can also be found in Ross' (2007) work. What I want to highlight here is, however, that the state is a multi-layered and fragmented entity in which a plurality of actors pursues very different interests. Building on Ross' notion of cultural contestation, I now turn to incorporating a multi-level governance perspective into his framework of cultural contestation.

\section{Theoretical and Methodological Approach}

Cultural contestation, according to Ross (2009), can be understood as the "inclusion and exclusion from a society's symbolic landscape and that such inclusion or exclusion tells us about the politics of acceptance, rejection and access to a society's resources and opportunities" (2009: 1). Ethnic and cultural groups seek to express their cultural identity in their symbolic landscape which comprises sacred sites and physical objects as well as music, language or public celebrations. Ross argues that since scholarship often solely focuses on competing interests, incompatible identities are overlooked. For this reason, he calls for examining symbolic landscapes and how they demonstrate the (perhaps missing) recognition of groups, how different groups refer to each other and themselves in psychocultural narratives as well as how the control of the symbolic landscape is related to resource allocation (Ross 2009: 1-2, see also Ross 2007).

As domestic heritage politics and the inherent allocation of resources among state and nonstate actors are strongly influenced by inscriptions of local tangible or intangible culture on the national level or at the UNESCO, it is necessary to incorporate a multi-level governance

\footnotetext{
${ }^{2}$ See also Louisa Schein (2000) on eroticization of ethnic minorities in China.
} 
perspective into the analysis. Taking a multi-level governance perspective facilitates an analysis of how different government levels interact. It therefore helps to explain "the dispersion of central government authority both vertically to actors located at other territorial levels, and horizontally to non-state actors" (Bach and Flinders 2004: 4). This fragmentation of authority between the central and subnational government levels, on the one hand, and between horizontal units and actors on the other, is moreover a key feature of the Chinese political system, commonly referred to as "fragmented authoritarianism" (Lieberthal and Oksenberg 1988; Mertha 2009). In this framework, decentralization processes are said to have resulted in a fragmentation between the lines of command, which provides subnational governments with greater leeway in policy implementation. Yet this greater leeway also results in competition between governmental units across the vertical and horizontal lines of authority, which leads to diverging policy implementation across government levels and geographical regions (Lieberthal and Oksenberg 1988: 21).

The fact that fragmentation between different government levels leads to competition, is important for understanding cultural contestation between the state and ethnic groups as it enables to acknowledge the plurality of official and vernacular narratives that have an impact on acts of cultural contestation. Moreover, cultural identities and expressions are linked to different scales, be it the local, regional or national. While building on Ross' work, this chapter thus seeks to extend his framework by acknowledging that the processes he described unfold on multiple levels and scales.

The PR China is as a significant case study to understand cultural contestation processes across levels or scales. Firstly, as mentioned above, the China exemplifies the ruptured and uneven developments in many state-nations across the Global South. Secondly, the Chinese party-state is a key actor in global heritage governance, particularly when examining its inscriptions on UNESCO heritage lists. To date, it has the second largest number of sites on the World Heritage List worldwide (52) (UNESCO 2017a), and the largest number of ICH practices on the UNESCO ICH Representative List (39) (UNESCO 2017b.). Finally, due to its rich ethnic diversity, the Chinese province of Yunnan is a critical case to understand how ethnic minorities contest cultural identities superscribed by different actors within the multilevel state.

The findings of this chapter are based on a case study of Yunnan province in which Lancang County, takes the center stage. Yet, local cultural contestation processes will be examined with reference to decisions made at the national, provincial and municipal (or prefectural) level. I collected data for this study by conducting several months of field work and engaging local officials, academics and cultural practitioners in semi-structured interviews. Moreover, a 
plurality of primary (laws, policies, government plans) and secondary sources (newspaper articles, academic studies) in Mandarin Chinese and English inform the study.

\section{Governmental Programs as an Opportunity for Fostering Cultural Identity}

Following the ratification of the UNESCO ICH Convention in 2004, the Chinese party-state, through the Ministry of Culture's ICH Department, implemented the Convention by creating $\mathrm{ICH}$ lists and an $\mathrm{ICH}$ inheritors program (SC 2005), the Chinese equivalent to a Living Human Treasures program (UNESCO 2002) in 2005. While ICH practices are inscribed on lists to raise awareness, the $\mathrm{ICH}$ inheritors program seeks to promote the transmission of $\mathrm{ICH}$ practices within local communities by financially supporting selected cultural practitioners (SC 2005, MC 2006). Government units at all administrative levels with decision-making powers (the national, provincial, municipal and county level) were asked to create their own $\mathrm{ICH}$ lists and $\mathrm{ICH}$ inheritor programs, resulting in a multi-level system of $\mathrm{ICH}$ safeguarding. After the county-level selects $\mathrm{ICH}$ practices and cultural practitioners from lower levels (village or township) for inclusion on its list, the municipal level creates its own $\mathrm{ICH}$ and $\mathrm{ICH}$ inheritor lists based on county-level programs. Thereby $\mathrm{ICH}$ practices and inheritors can be promoted "up the ladder" to eventually become national representatives of Chinese ICH (Maags 2018 forthcoming, see also Bodolec 2012: 259).

As the inscription of $\mathrm{ICH}$ items (and in part $\mathrm{ICH}$ inheritors) on lists at the next governmental (e.g. municipal level) level generates political and economic benefits for government officials on that level (county level), local governments compete to promote their selected cultural practice "up the ladder" (Maags 2018 forthcoming). Firstly, this competition is due to the establishment of such lists and programs on each administrative level. Secondly, as outlined above, the fragmentation of authority between different government units along the horizontal and vertical line fosters competition, as local governments attempt to obtain a promotion or win superordinate level funding (Zhong 2003: 87; Heberer and Trappel 2013: 1056) for local $\mathrm{ICH}$ safeguarding projects. As described elsewhere in greater detail (Maags 2018 forthcoming) the multi-level policy implementation and the fragmented authority structure have resulted in cultural contestation between local communities who all seek to be selected to represent a local $\mathrm{ICH}$, which is prevalent in many localities albeit in different variations, at the next level. As a result, on the one hand, the promotion of $\mathrm{ICH}$ practices and inheritors "up the ladder" creates contestation and conflict between local communities (Maags 2018 forthcoming).

Yet, on the other hand, the superordinate government levels select from these local $\mathrm{ICH}$ practices to forge a regional, provincial or national cultural identity that is to promote social cohesion and pride. Fostering a national identity is especially of importance as China is 
home to 56 officially recognized ethnic minorities - a classification which was devised in the Ethnic Identification Project ${ }^{3}$ from 1950s to the 1980s (Wang 2015: 4). To increase social cohesion, the party-state has increasingly selected $\mathrm{ICH}$ practices of ethnic minorities to UNESCO representative lists ${ }^{4}$, as it seeks to promote the narrative of a "unified multi-ethnic state", and thereby an inclusive multi-ethnic national identity. In this narrative the party-state emphasizes a supposed historical unity of different ethnic groups to display the uniting of different ethnic groups as natural and inevitable (Bird 2017: 3). Inscriptions of ethnic minorities' cultural sites and practices on UNESCO lists, further substantiate this narrative and, according to Shepherd (2009) enhances Chinese political claim over these territories.

In the case of Yunnan province, the promotion of the narrative of a "unified multi-ethnic state" is particularly important as it is home to the largest diversity of ethnic groups in the country, being inhabited by 26 ethnic groups (Yunnan gov. 2015). Yunnan's official documents therefore foster a similar narrative. In Art. 1 of Yunnan's ICH policy of 2005, for instance, the prime objective of safeguarding $\mathrm{ICH}$ is allegedly to promote "patriotism", "strengthen Yunnan's economic and social development" and "preserve national unity" (Art. 1; YNCD 2005). While maintaining social cohesion is a main objective, the provinces' strong economic reliance on the tourism industry is another. As the tourism industry, in addition to agriculture and mining, are the provincial pillar industries (Britannica 2016), the safeguarding of ethnic minority culture is tantamount to preserving a key resource needed for economic development. Yunnan thus implements central policies in which "Heritage construction is a core feature of regional development strategies, especially in the historically poor and ethnically diverse regions of the southwest" (Evans and Rowlands 2015: 272).

To promote social cohesion and economic development Yunnan province is very eager to develop its provincial ICH safeguarding. For instance, already in the late 1990s Yunnan established policies for the safeguarding of traditional cultural practices (Liang 2013: 61-62). In addition, it has successfully inscribed $105 \mathrm{ICH}$ practices on national ICH lists (Xinhua 2017) and established $66 \mathrm{ICH}$ environmental protection zones in Yunnan, which are inhabited by 21 different ethnic groups (YCB 2014). Yunnan's eagerness to inscribe ICH practices and zones has at times caused conflict between ethnic groups. To reduce potential cultural contestation and conflicts around the designation of $\mathrm{ICH}$ items and safeguarding areas among ethnic groups, who all seek to have their $\mathrm{ICH}$ practice listed at the national level and thus enjoy national recognition, the provincial government attempts to recommend equal numbers of $\mathrm{ICH}$ practices from each ethnic minority to the national level. However, ethnic

\footnotetext{
${ }^{3}$ In this "Project" ethnic groups who identified as a separate ethnicity were asked to officially register as an ethnic minority. Yet, ethnic groups who failed to apply for recognition did not obtain ethnic minority status and thus do not enjoy minority rights (Wang 2015: 4).

${ }^{4}$ Among the first $10 \mathrm{ICH}$ items the Chinese party-state nominated for the UNESCO ICH list five are representing ethnic minority culture (UNESCO 2017c).
} 
sub-groups, who do not identify with the culture of the larger ethnic group, do not feel represented (Blumenfield 2018 forthcoming). As one prominent $\mathrm{ICH}$ expert noted, the designation of a territory as "Cultural Landscape of the Honghe Hani Rice Terraces" in 2013 at UNESCO similarly caused contestation between ethnic groups, as the region is not only inhabited by the Hani ethnic group (Interview 7; see also UNESCO 2013). The designation of $\mathrm{ICH}$ practices and zones has thus led to the glossing over of ethnic differences which have created tensions between ethnic groups, who contest state programs and inscriptions which violate their cultural identity.

As Yunnan is one of the poorest provinces in PR China ${ }^{5}$ (Finance Sina 2017), it is eager to make use of the national financial incentive structure to fund its promotion of $\mathrm{ICH}$ safeguarding. The central government rewards local policy innovation by declaring local best practices as "models" for national emulation and providing these models with additional central funding (Zhong 2003; Heilmann 2008). Yunnan is eager to use its leeway in policy formulation and implementation to be successful in the national competition for central level funding. As it is home to many ethnic minorities which are often allowed more extensive leeway in policy formulation and implementation due to their "self-governing" status ${ }^{6}$, subprovincial governments can potentially use their greater leeway for policy innovation to compete for national-level funding. One example of such a model unit is Lancang County (in Pu'er municipality) in the very south of Yunnan province.

Lancang County (Lancang Lahuzu Zizhi Xian) is a poor, "self-governing" jurisdiction in the south of Yunnan bordering Myanmar. The County is home to eight different ethnic groups of which the largest group are the Lahu. To promote local Lahu culture, the county government began to develop its safeguarding measures from an early stage on. Following the ratification of the UNESCO ICH Convention in 2003, the County launched its "Lancang Properous County" initiative which is aimed at promoting traditional Lahu culture in the domestic and international realm (Xinhua 2014). This initiative was followed by a series of county-level policies $^{7}$ with similar aims in 2008 (revised in 2012) (LCCC 2015a). In these and other policies, the Lancang government stipulates that each village in its jurisdiction must establish a cultural performance troupe and a cultural center where local residents can receive lessons in $\mathrm{ICH}$ practices and use musical instruments free of charge. Moreover, $\mathrm{ICH}$ practices and inheritors are to be promoted for the inscription in local and superordinate $\mathrm{ICH}$ lists (Interview 42). The County has been very successful. Two of their ICH practices, the Mupamipa legend

\footnotetext{
5 Yunnan's provincial GDP ranks $23^{\text {rd }}$ out of the 31 provinces and autonomous regions (Finance Sina 2017).

${ }^{6}$ The PRC's Constitution (2004) stipulates that ethnic minorities have the right to pass local regulations, manage their own budget (to be approved by central authorities) and government departments need to be headed by members of the ethnic groups (Art. 112-122) (NPC 2004).

7 These policies include "Traditional Ethnic Folk Culture Protection Regulations" (revised in 2012) as well as the "Lancang Lahu Minority Self-governing County Methods on Strengthening the Implementation of County level ICH Protection and Transmission" (LCCC 2015a).
} 
and the Lusheng dance were inscribed on national ICH list in 2006 (China.com 2007a, 2007b). Moreover, due to their safeguarding efforts, Lancang was identified as "model county" for $\mathrm{ICH}$ safeguarding by the central government. These rewards have also contributed to local pride, as an interview with one county $\mathrm{ICH}$ official indicates:

This is not meant to sing one's own praise, [but] Lancang is used as a model [lit. "typical example"]. In the whole province, our transmission of $\mathrm{ICH}$ items, our work achievements and the atmosphere of our culture are [considered to be] all very good. (Interview 42).

As a result of being named a model county, Lancang is able to benefit from the national financial incentive structure.

Along with the promotion of Lahu culture, the county government is disseminating a narrative around Lancang County being a "Global Lahu Cultural Centre". A central theme of their narrative is the Mupamipa (Creating Heaven, Creating Earth) legend which tells the story of the origin of the Lahu ethnic group and speaks about their society, religion and culture as well as their journey to the southwest of Yunnan. In this narrative, Lancang is portrayed at being the center of Lahu culture. This narrative and the Mupamipa legend has been tangiblized through the creation of a symbolic cultural landscape. As, according to legend, the Lahu were born out of a calabash (Interview 42), in recent years, images from the legend, especially the calabash, have been placed across the city (see Illustration 1). For instance, a new square has been built in the midst of the city, in which a large calabash decorates the center. According to a local cultural official, the square is to provide public space to perform Lahu cultural practices (Interview 42).

Illustration 1: The Calabash in the Newly Developed Town Square in Lancang County 


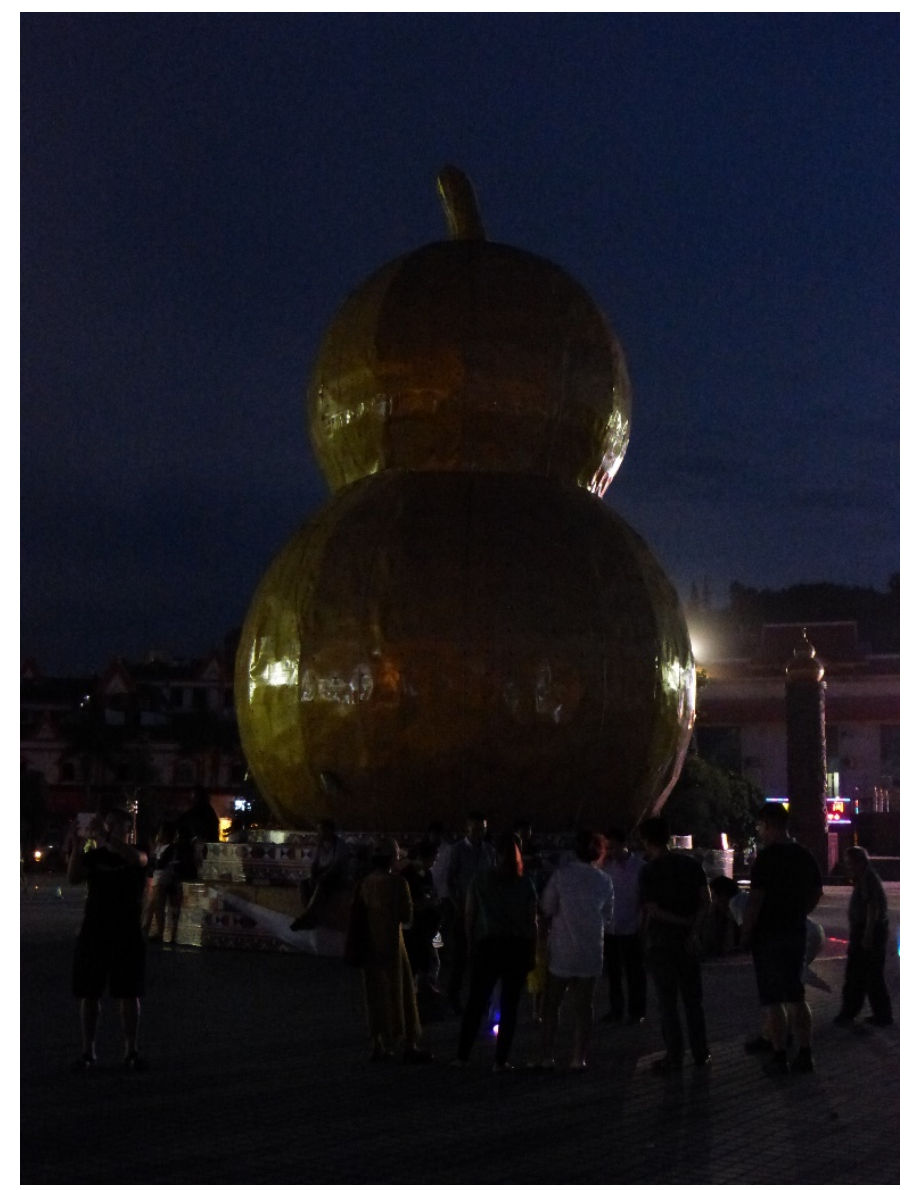

(Source: author)

Moreover, a new park has been created which is filled with statues representing events within the Mupamipa legend as well as displaying the Lahu or other ethnic minorities of the region (see Illustration 2).

Illustration 2: Statue in the New Park in Lancang Depicting the Mupamipa Legend 


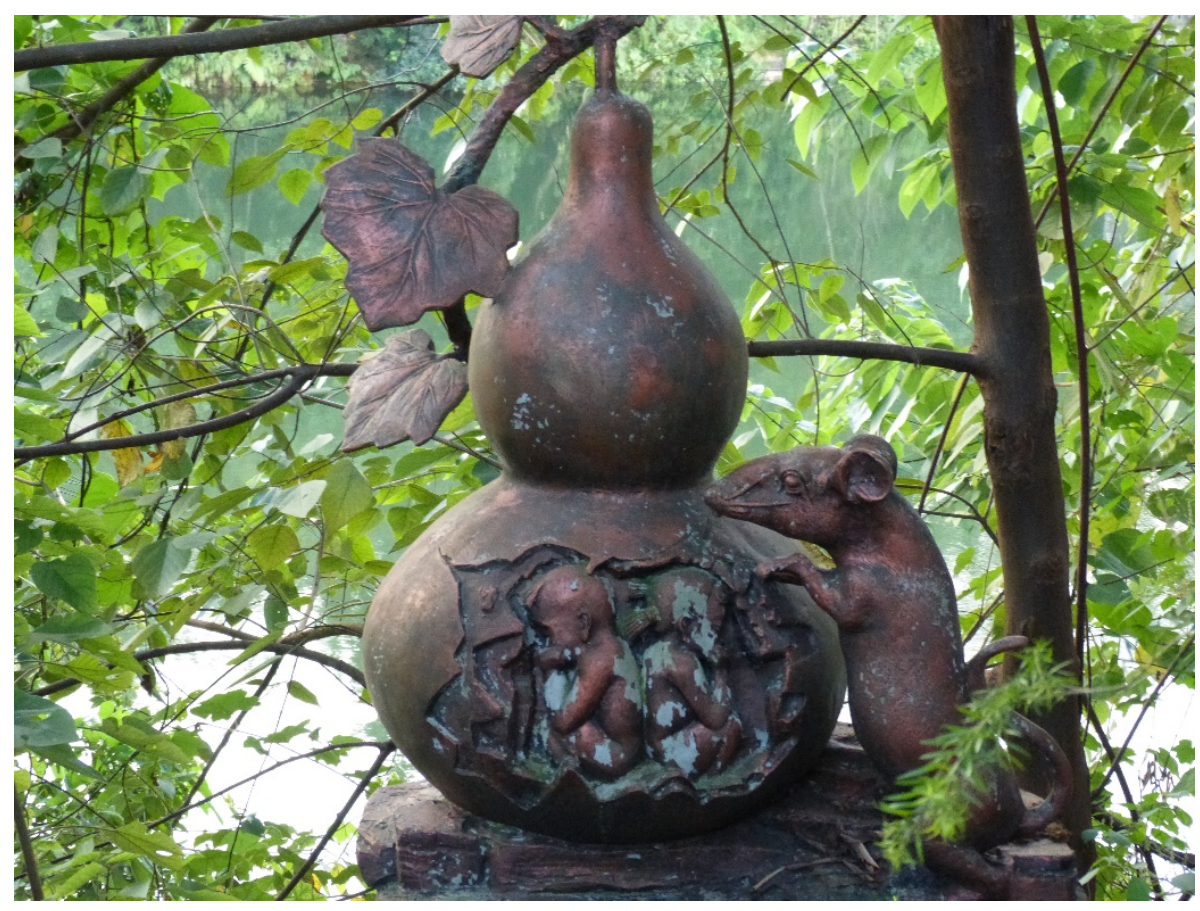

(Source: author)

Again, the park incorporates small stages where traditional dances and musical performances can be displayed. The city environment has thus been recreated into a symbolic cultural landscape demonstrating Lahu culture. According to the county government, its main objective behind the rebranding and promotion of $\mathrm{ICH}$ practices has been the preservation of Lahu ethnic culture. As a third of the Lahu ethnic minority worldwide ${ }^{8}$ live in the county, the county government - whose staff are themselves Lahu - sees itself as the wardens of traditional Lahu culture. They therefore promote traditional dances, songs and legends lie at the core of Lahu culture (Interview 42).

The Mupamipa legend furthermore since the 1950s has been interpreted along the lines of official narratives, using it as evidence of a supposed origin of the Lahu in the north-western Qinghai Plain in an attempt to integrate the Lahu into the history of the Chinese state (Ma 2009: 111-114). Although this supposed origin, which scholars such as Ma (2009) contest, is not contested by the Lahu themselves, the Mupamipa legend provides a "politically safe" opportunity to create a narrative and symbolic cultural landscape which highlights and celebrates the distinctiveness of Lahu culture vis-à-vis the dominant Han culture. This celebration of distinctiveness in opposition to the Han majority, historically and at present, furthermore forms the basis of Lahu cultural identity. Ma (2013), for instance, argues that

The Lahu identity and Lahu culture have been mobilized under the conditions of the arrival of the state powers in the mountains. Without the state's penetration there

\footnotetext{
${ }^{8}$ The other two thirds of the Lahu lives in other parts of China or in neighbouring regions in Myanmar and Thailand, see Ma 2013: 8-9.
} 
would have been no political-religion system or Lahu identity, based on detailed historical research on this frontier (Ma 2013: 9).

The promotion of the legend can thus support Lahu cultural identity as well as the safeguarding of local ICH practices.

Overall, Lancang's county government has thus seized the opportunity of the Chinese leadership's greater attention to traditional culture to celebrate its cultural identity and popularize Lahu culture more broadly. While the safeguarding measures foster the preservation of Lahu culture and identity in a rapidly changing environment, the national ICH lists demonstrate national social recognition of Lahu culture which enhances local pride in traditional ethnic culture. As one $\mathrm{ICH}$ inheritor proudly explained:

at the moment we have [performed] in Shanghai, Beijing [and these cities]. They have all [experienced] our Lahu singing, our Lahu minority dance, so they know a little, have seen a little (Interview 45).

The county government has thus been successful in promoting Lahu traditional culture beyond Yunnan, which has fostered local cultural identity and pride. Moreover, national recognition also equals financial support, which is needed to fund the safeguarding measures. Ultimately, national recognition and local safeguarding measures further emphasize the uniqueness and distinctiveness of Lahu culture vis-à-vis the Han as well as other ethnic minorities in the region.

\section{Multi-level Threats to Local Cultural Narratives and Identities}

Although the nationwide recognition and promotion of Lahu ethnic minority culture can be regarded as a success, as Lancang is now able to showcase their culture and distinctiveness domestically and internationally, their success does not protect them from interests, strategies and cultural identities promoted at other government levels. In Pu'er, the municipality to which Lancang county belongs, for instance, a different narrative has dominated. In Pu'er municipality as a whole the Deang, Bulang, Hani and Wa ethnic groups are most numerous (Pu'er gov. 2015; Ethnic China 2016). The regions closer to the municipality's capital, have moreover historically been part of an ancient "Tea Horse Road" in China, which linked the tea production in the area to consumers in other parts of China. After Pu'er tea re-gained popularity in the early 2000s (Zhang 2014: 8), the provincial government in Kunming decided to rebrand the municipality along tea culture and production. As a part of this strategy, the municipality which had formerly been known as Simao was renamed into Pu'er (the name of the tea) in 2008 (Zhang 2014: 82). Rebranding the municipality's capital along tea culture, furthermore included the nomination of its tea mountains as "Ancient Tea Plantations of Jingmai Mountain in Pu'er" for inscription on the World Heritage List. To date, however, the nomination awaits approval (UNESCO 2016). As a result of the rebranding, the 
Pu'er tea industry has boomed, sparking a subsequent boom in the tourism and cultural industries (PETA 2016).

Thus, in Pu'er a different narrative and symbolic cultural landscape as taken shape. While it celebrates its rich ethnic diversity, it's regional identity is strongly focused on tea culture, which is only part of some ethnic minority cultures but not all (Interview 43). Field visits showed that in comparison to Lancang, Pu'er's symbolic cultural landscape is not as much shaped by the display of certain objects such as the calabash, but strongly visible in the transformation of its cultural space. Across the city, tea houses have opened, which celebrate the drinking of tea through tea ceremonies. Pu'er tea and local ethnic minority culture are common sights on billboards and tourism advertisement. Overall, local residents appear to have "rediscovered" Pu'er tea and related cultural practices and rituals.

While Pu'er is said to have started to promote its local tea already since the mid-1990s (Zhang 2014: 42), the provincial government has had a strong influence on the acceleration and expansion of Pu'er's urban rebranding. Already in the mid-2000s, the provincial government issued policies focusing on enhancing the development if the provincial tea industry (Yunnan gov. 2005). Soon after Kunming commenced to invest into the Pu'er tea industry by founding state-owned tea enterprises. In subsequent years it developed a brand and marketing strategy for Pu'er tea which was promoted during the 2008 Olympics as well as the 2010 World Expo in Shanghai. For the Pu'er municipal government this development has been highly advantageous as it strongly seeks to foster its economic development by enhancing its tea, tourism and cultural industries (PECB 2012).

However, while the promotion of Pu'er as a tea culture destination has been to the benefit of the municipality, it does not necessarily support Lancang County's interests and cultural identity. In 2012, for instance, the provincial government declared that it would establish a historical cultural tourism zone displaying the origin of tea. According to this plan, three adjoining counties within Pu'er municipality, including Lancang, are to be promoted as a "Tea Origin Culture Park" in order to transform the region into one of Yunnan's ten largest historical cultural tourism zones. In fact, Lancang would be situated at the core of this park which offers tourists the experience of tea culture, entertainment, shops, hotels and ethnic minority culture. At the time of writing, the provincial government was seeking investors (Yunnan gov. 2015b), who in addition to county governments such as Lancang (LTCA 2016) are to fund the establishment of the park.

For Lancang County and its government's dream of becoming a "Global Lahu Cultural Centre" the provincial government's plans create a dilemma. On the one hand, the County is extremely poor (in Yunnan and in national terms) and women have been marrying Han to move out of the region (Ma 2013: 3-12). It could therefore benefit from the economic and 
infrastructure development which a new tourism zone would facilitate. As noted above, Lancang County is focusing on safeguarding and promoting its performing arts, such as traditional Lahu dances, songs and myths. An integration into a tourism zone could provide these traditional artists and amateurs with the opportunity to present their art as well as generate an income, thus enabling a sustainable safeguarding of these ICH practices.

On the other hand, Pu'er municipality's cultural identity and narratives directly run counter to Lancang County's plans of establishing themselves as a Global Lahu Cultural Center. As a local ICH official argued, although Lahu culture has incorporated some elements of other ethnic minorities, tea culture is not part of Lahu culture but rather related to the Bulang ethnic minority (Interview 43). One ICH official for instance argued that

Our (genesis) legend has always continued to develop, we sing it every day and every night. The songs and dances have special characteristics. Speaking of other ethnic minorities, for instance, the Bulang ethnic minority, they like tea, this minorities' $\mathrm{ICH}$ projects evolve around tea culture. They have a totally different focus than we do (Interview 42).

By being incorporated into a larger tourism zone which is linked to a different cultural identity and narrative, Lancang would thus face the challenge of being subsumed under a larger, regional identity which was constructed by superordinate government levels in an attempt to promote economic development. While the project is still in the making, Lancang appears to react to these 2012 plans by more strongly promoting its county as a "Global Lahu Cultural Centre". It for instance has adopted new local policies (LCCC 2015a), is popularizing its culture in TV shows and movies, and is winning national rewards, for instance, "China Village of Folk Culture Art" and "China Cultural Advanced County" (LCCC 2016, People's Daily 2016, Yunnan Network 2016). It thereby attempts to strengthen its cultural identity and symbolic cultural landscape at a time when competing cultural identities are promoted which might undermine Lahu cultural identity. In doing so, it produces counter-narratives which tell a different story of the locality, running against the broader, regional narratives. In contrast to engaging in open contestation of superordinate plans, Lancang has thus chosen to not directly oppose state-sanctioned narratives and plans, but to subvert them indirectly by maintaining and promoting its own, alternative narratives.

\section{Ambiguous Effects of China's Multi-level ICH Safeguarding System}

Whereas the introduction of an $\mathrm{ICH}$ safeguarding system in China has provided ethnic groups such as the Lahu with the opportunity to enhance safeguarding and promotion of their $\mathrm{ICH}$ practices and thereby to strengthen their cultural identity, the simultaneous safeguarding and promotion efforts on other governmental levels may contradict or undermine local efforts in case they are not in line with superordinate narratives. On the one hand, the Lahu's 
cultural identity has been reinforced by the national recognition and popularization of its cultural practices such as the Lusheng dance and the Mupamipa legend. As this national recognition goes hand in hand with financial support and several awards, as for instance to be named a "model county", and somewhat with a gain in political and economic power. On the other hand, despite its recognition and greater power, it remains to be a poor county which needs to oblige with superordinate development plans, even when they run counter its own plans and narratives. Here Lancang County appears to face a dilemma between embracing the development plans it so desperately needs to provide its residents with employment and growth prospects, while fearing that these development plans and related narratives will undermine its own narratives and by extension cultural identity.

Lancang County's response to this dilemma appears to have been to not openly contest any plans or narratives developed by superordinate levels, although the County government might lobby for incorporation or acknowledgement of its own plans and narratives behind closed doors. It rather appears to strengthen its own narratives and cultural identity by further developing their own $\mathrm{ICH}$ safeguarding measures and symbolic cultural landscape, e.g. by creating a large square displaying Mupamipa symbols such as the calabash. In doing so, its symbolic cultural landscape and narratives are reinforced and demonstrate a counternarrative vis-à-vis other, regional narratives which might undermine its cultural identity.

Although local communities across China have also openly contested state narratives and development projects (see e.g. Svensson 2006; Kang 2009: 240), a more indirect or covert form of cultural contestation appears to be a common strategy among local ethnic groups, and by extension any cultural group, who do not have the power or agency to openly defy and contest superordinate narratives and plans. Yu (2015) for instance, has similarly argued that local Miao communities create and disseminate counter-narratives as well as secretly and publicly perform their rituals which go against official interpretations so that "Vernacular narratives, beliefs, spaces and practices have spread beyond the reach of the state, even as the country undergoes massive economic and social transformation, and the more recent global surge of interest in safeguarding ICH" (2015: 1032). Similarly, Evans and Rowlands (2015) have pointed out that the sustainability of local initiatives "depends on the successful accommodation of the state's political, economic and commercial interests through appropriating and contesting the commodification of heritage and negotiating complex relationships between individuals, communities, entrepreneurs and official agencies (2015: 280, emphasis in original). Cultural contestation in authoritarian China can therefore take more indirect forms in which government plans and narratives are not openly contested, 
even accommodated to a certain extent, while subtle counternarratives and measures simultaneously undermine superordinate efforts.

However, many of the studies which elaborate on these indirect forms of cultural contestation portray a dichotomy between local communities and the state in which local communities are fighting against state control and repression. Although this picture accurately depicts many instances of cultural contestation, it is necessary to consider the different actors and administrative levels within multi-level governance systems such as that of the PRC. Different government levels may pursue different interests and strategies as well as disseminate different narratives. As $\mathrm{Yu}$ (2015) has argued, in China central government policy is often contested by local governments, as expressed in the local idiom "Up, there is policy. Bottom, there is countermeasure' (shang you zheng ce, xia you dui ce)" (2015: 1022). Cultural contestation therefore may arise due to a locality being caught up in a multilevel governance structure which all have different interests, strategies as well as narratives and identities. Moreover, the dichotomy between state and society glosses over the fact that government officials are also part of the local community and, especially when their own local cultural identity is concerned, may attempt to use opportunities provided by the state such as $\mathrm{ICH}$ lists and financial incentive structures to safeguard their local heritage and create a symbolic cultural landscape which reinforces their cultural identity.

In the case of Lancang County it appears that the local officials have used their available resources and power to safeguard Lahu ICH practices by promoting local $\mathrm{ICH}$ practices "up the ladder" of the multi-level $\mathrm{ICH}$ inscription system or by establishing culture centers and troupes. In doing so, they reinforce local cultural and historical narratives and cultural identity, while simultaneously complying with central policies calling for the establishment of local ICH safeguarding measures and using heritage as a development strategy for poor, ethnically diverse regions.

\section{Conclusion}

The introduction of an $\mathrm{ICH}$ safeguarding system in the Chinese multj-ethnic, multi-level state has had ambiguous effects. While the party-state's recent increase in attention towards safeguarding of $\mathrm{ICH}$ practices has been, among others, an effort to strengthen nationbuilding and nationalist sentiments among its populace, governmental programs also generate cultural conflicts among ethnic and cultural groups as well as between these groups and the state. While many conflicts arise due to the artificial classification of ethnic groups during the 1950s and the central strategy of using ethnicity as a resource to develop poor and remote regions on Chinese periphery, this chapter has shown that the multiple government levels and scales at which identities are formed similarly create cultural 
contestations. While some local communities and groups chose to openly challenge imposed or competing narratives and cultural identities, others select more indirect and subtle ways of contestation which are based on creating counter-narratives and reinforcing their local cultural identity through developing a symbolic cultural landscape. Moreover, the dichotomy between "state" and "society" is not always as clear cut as state officials may be members of an ethnic minority and thus have an intrinsic motivation to use opportunities that the state provides to safeguard and promote their ethnic cultural identity. Since the People's Republic is an authoritarian state, however, cultural contestation may take more subtle and indirect forms of cultural contestation which are based on counter-narratives and identities.

The Chinese party-state can be understood through the notion of the "robustly multinational" state-nation (Stepan et al. 2010). On the one hand, the party-state has engendered "strong identification and loyalty from their citizens" (Stepan et al. 2010: 1) by promoting a national identity through the narrative of a multi-ethnic state (Brady 2012: 3) and fostering a "performance-based legitimacy" (Holbig and Gilley 2010) which promises economic growth and future prosperity. On the other hand, the national narrative of a multi-ethnic state continues to be contested by certain groups, for instance, among the Tibetans and Uyghurs (Bhattacharya 2008), who "in the name of nationalism and self-determination, advance claims of independence" (Stepan et al. 2010: 1). However, although Stepan et al.'s (2010) conception of a state-nation is based on democratic systems, many of which are federalist in nature (Stepan et al. 2010: 22) and the Chinese party-state is an authoritarian, centralized state, this chapter demonstrates that China displays similarities with other state nations in the Global South. Firstly, due to its fragmentation, subnational administrative levels, especially provinces, obtain greater leeway in policy formulation, thereby enabling similar dynamics as in federalist states. Secondly, there are separatist movements among ethnic minority groups and at times open forms of cultural contestation against imposed narratives and identities by the party-state. However, due to the authoritarian nature of the state it also gives way to more indirect and subtle forms of contestation which simultaneously seek to accommodate and contest state competing state narratives and identities.

To understand the complexities of cultural contestation, particularly in multi-ethnic states, more research needs to be conducted which incorporate alternative explanatory frameworks such as that proposed by Ross (2007) which highlight the role of cultural identity and narratives in these processes. This chapter has sought to build on Ross' framework and to extend it by incorporating a multi-level perspective. While this chapter has briefly related its findings to the literature of state-nations, more research is needed to demonstrate how cultural contestation emerges and unfolds in different types of state-nations and nation-states, 
in order to comprehend how the differences in ethnic composition, cultural homogeneity and political systems have an impact on cultural contestation and with what effects.

\section{Bibliography}

Bache, I. and M. Flinders (2004): Introduction, in I. Bache and M. Flinders (eds): Multi-level Governance. New York: Oxford University Press, 1-14.

Barmé, Geremie (1999): IN THE RED. On Contemporary Chinese Culture. New York: Columbia University Press.

Bird, Joshua (2018): Economic Development in China's Northwest: Entrepreneurship and Identity Along China's Multi-ethnic Borders. London, New York: Routledge.

Blumenfield, Tami (2018): Recognition and Misrecognition: The Politics of Intangible Cultural Heritage in Southwest China, in Christina Maags and Marina Svensson, Chinese Cultural Heritage in the Making. Experiences, Negotiations and Contestations. Amsterdam: IIAS/Amsterdam University Press, forthcoming Spring 2018.

Blumenfield, Tami and Helaine Silverman (2013): "Cultural Heritage Politics in China: An Introduction", in Tami Blumenfield and Helaine Silverman, Cultural Heritage Politics in China, New York: Springer, pp 51-71.

Bhattacharya, Abanti (2008): Conceptualising Uyghur separatism in Chinese nationalism, Strategic Analysis, 27 (3), 357-381.

Bodolec, Caroline (2012): The Chinese Paper-Cut: From Local Inventories to the UNESCO Representative List of the Intangible Cultural Heritage of Humanity. In: Regina F. Bendix; Aditya Eggert and Arnika Peselmann (eds.): Heritage Regimes and the State. Göttingen Studies in Cultural Property (Volume 6). Göttingen: Universitätsverlag Göttingen, 249-464.

Brady, Anne-Marie (2012): Ethnicity and the State in Contemporary China, Journal of Current Chinese Affairs, 41 (4), 3-9.

Britannica (2016): Yunnan, https://www.britannica.com/place/Yunnan.

Chau, Adam Yuet (2005): The Politics of Legitimation and the Revival of Popular Religion in Shaanbei, North-Central China. In: Modern China, 31 (2), 236-278.

Chen, Zhiqin (2015): For Who to Conserve Intangible Cultural Heritage: The Dislocated Agency of Folk Belief Practitioners and the Reproduction of Local Culture. In: Asian Ethnology, 74 (2), 307-334.

China.com

(2007a): Mapamipa, http://www.china.com.cn/culture/zhuanti/whycml/200706/13/content 8384459.htm.

China.com (2007b): Yi Ethnic Minority Hulusheng Dance, http://www.china.com.cn/culture/zhuanti/whycml/200706/13/content 8384294.htm.

Cheung, Kelvin Chi-Kin (2012): Away from socialism, towards Chinese characteristics: Confucianism and the futures of Chinese nationalism, China Information, 26 (2), 205-218.

Duara, Prasenjit (2010): The Historical Roots and Character of Secularism in China, in Wang Gungwu, ed. China and International Relations: The Chinese View. London: Routledge.

Ethnic China (2016): Puer (Simao) Prefecture, http://www.ethnicchina.com/Geo/Yunnan/puerintro.htm. 
Evans, Harriet and Michael Rowlands (2015): Reconceptualising Heritage in China: Museums, Development and the Shifting Dynamics of Power, in Paul Basu and Wayne Modest (eds): Museums, Heritage and International Development. New York: Routledge.

Finance Sina (2016): Provincial GDPs of 2016 according to rank, http://finance.sina.com.cn/china/gnci/2017-02-07/doc-ifyaexzn9124761.shtml

Gao, Yuan (1987): Born Red. A Chronicle of the Cultural Revolution. Stanford: Stanford University Press.

Gladney, Dru C. (1996): Muslim Chinese: Ethnic Nationalism in the People's Republic. Cambridge, M.A.: Harvard East Asian Monographs.

Hafstein, Vladimir (2009): Intangible Heritage as a List: From Masterpieces to Representation. In: Laurajane Smith and Natsuko Akagawa (eds.): Intangible Heritage. London and New York: Routledge, 93-111.

Harrison, R. (ed.) (2010): Understanding the Politics of Heritage. Manchester: Manchester University Press.

Heberer, Thomas and Rene Trappel (2013): Evaluation Processes, Local Cadres' Behaviour and Local Development Processes, Journal of Contemporary China, 22 (84), 1048-1066.

Heilmann, Sebastian (2008): Policy Experimentation in China's Economic Rise, Studies on Contemporary International Development, 43, 1-26.

Holbig, Heike and Bruce Gilley (2010): In Search of Legitimacy in Post-revolutionary China: Bringing Ideology and Governance Back In, GIGA Working Papers, 127/2010.

Kang, Xiaofei (2009): Two Temples, Three Religions, and a Tourist Attraction. Contesting Sacred Space on China's Ethnic Frontier, Modern China, 35 (3), 227-255.

Liang, Yongjia (2013): Turning Gwer Sa La Festival into Intangible Cultural Heritage: State Superscription of Popular Religion in Southwest China, China: An International Journal, 11 (2), 58-75.

LCCC (Lancang Culture Center) (2015a): Langcang County's ICH Protection Work Circumstances, obtained from the Lancang Culture Center during field research in summer 2015.

LCCC (Lancang Culture Center) (2015b): Situation of Lancang County's Culture Center, http://www.lcwhg. net/portal.php?mod=view\&aid=19.

LCCC (Lancang Culture Center) (2016): Deepening and Advancing the Strategy of Prominent County of Lahu Culture' Actively Establishes National Cultural Advanced County, http://www.pelcxxw.cn/kllh/02544195003592422520 .

Lieberthal, Kenneth and Michael Oksenberg (1988): Policy-making in China. Leaders, Structures and Processes. Princeton University Press.

Lieberthal, Kenneth and David Lampton (eds.) (1992): Bureaucracy, Politics, and Decision Making in Post-Mao China. Berkeley: University of California Press.

LCTA (Lancang Tourism Administration) (2016): Project for Establishing Tea Origin Historic Cultural Tourism in Three Adjoining Counties in Pu'er Municipality, http://news.jkyscsmc.com/zcnsgddyy/2819.html.

NPC (National People's Congress) (2004): Constitution of the People's Republic of China, http://www.npc.gov.cn/englishnpc/Constitution/node 2825.htm. 
Ma, Jianxiong (2009): Local Knowledge Constructed by the State. Reinterpreting Myths and Imagining the Migration History of the Lahu in Yunnan Province, China,

Ma, Jianxiong (2013): The Lahu Minority in Southwest China: A Response to Ethnic Marginalization on the Frontier. New York: Routledge.

Maags, Christina (2018): Creating a Race to the Top: Hierarchies and Competition within the Chinese ICH Transmitters System. In. Christina Maags and Marina Svensson (eds): Chinese Cultural Heritage in the Making: Experiences, Negotiations and Contestations. Amsterdam: Amsterdam University Press, forthcoming.

Maags, Christina and Heike Holbig (2016): Replicating Elite Dominance in Intangible Cultural Heritage Safeguarding: The Role of Local Government-Scholar Networks in China, International Journal of Cultural Property, 23, 71- 97.

Mertha, Andrew (2009): Fragmented Authoritarianism 2.0, The China Quarterly, 200, 9951012

MOC (PRC Ministry of Culture) (2006): National ICH Safeguarding and Provisional Administration

Methods,

http://59.252.212.6/auto255/200612/t20061215 13005.html?keywords=\%E9\%9D\%9E\%E7\% 89\%A9\%E8\%B4\%A8\%E6\%96\%87\%E5\%8C\%96\%E9\%81\%97\%E4\%BA\%A7.

PECB (Pu'er Culture Bureau) (2012): Pu'er Municipality People's Government's Implementation Opinion on Strengthening the Establishment of a System on Public Culture Services that Benefit the People, http://xxgk.yn.gov.cn/Z M 004/Info Detail.aspx?DocumentKeylD=DB6B9A2EE748417C861 8D55A87441B75.

People's Daily (2016): Summary of the great achievements of Lancang County's deepening and progressing "Lahu Culture Famous County" Strategy, http://yn.people.com.cn/news/yunnan/n2/2016/0706/c376835-28623182.html.

PETA (Pu'er Tourism Administration) (2016): Pu'er Tourism News - Number 11, http://www.puerta.gov.cn/content.aspx?id=479378914048.

Pu'er gov. (Pu'er Municipal Government) (2015a): Pu'er Situation, http://www.puershi.gov.cn/pegk/07643077707004600223.

Ross, Marc Howard (2007): Introduction: easy questions and hard answers, what are they fighting about? in Cultural Contestation in Ethnic Conflict. Cambridge: Cambridge University Press.

Ross, Marc Howard (ed.) (2009): Culture and Belonging in Divided Societies: Contestation and Symbolic Landscapes. Philadelphia: University of Pennsylvania Press.

SC (State Council) (2005): State Council's Opinion on Strengthening Intangible Cultural Heritage Protection Work, http://www.gov.cn/zwgk/2005-08/15/content 21681.htm.

Schein, Louisa (2000): Minority Rules: The Miao and the Feminine in China's Cultural Politics. Duke University Press.

Shepherd, Robert (2009): Cultural Heritage, UNESCO, and the Chinese State Whose Heritage and for Whom? Heritage Management, 2 (1), 55-79.

Shepherd, Robert and Larry Yu (2012): Heritage Management, Tourism, and Governance in China: Managing the Past to Serve the Present. New York: Springer. 
Stepan, Alfred; Juan J. Linz, and Yogendra Yadav (2010): Crafting State-Nations. India and Other Multinational Democracies. John Hopkins University Press.

Svensson, Marina (2006): In the Ancestors' Shadow: Cultural Heritage Contestations in Chinese Villages. Lund: Center for East and South- East Asian Studies, http://isites.harvard.edu/fs/docs/icb.topic1466881.files/Svensson\%20ancestors shadow.doc.

UNESCO (2002): Guidelines for the Establishment of Living Human Treasures Systems, online: http://unesdoc.unesco.org/images/0012/001295/129520eo.pdf.

UNESCO (2003): Convention for the Safeguarding of the Intangible Cultural Heritage 2003, http://portal.unesco.org/en/ev.phpURL ID=17716\&URL DO=DO TOPIC\&URL SECTION=2 01.html.

UNESCO (2013): Cultural Landscape of Honghe Hani Rice Terraces, http://whc.unesco.org/en/list/1111.

UNESCO (2016): Ancient Tea Plantations of Jingmai Mountain in Pu'er, http://whc.unesco.org/en/tentativelists/5810/ .

UNESCO (2017a): China, http://whc.unesco.org/en/statesparties/cn.

UNESCO (2017b): China and the 2003 Convention, https://ich.unesco.org/en/state/china-CN. UNESCO (2017c): China and the 2003 Convention, https://ich.unesco.org/en/state/china-CN.

Wang, Linzhu (2015): Identification of Ethnic Minorities in China. Asian-Pacific Law \& Policy Journal, 16 (2), 1-21.

Waterton, Emma (2010): Politics, Policy and the Discourses of Heritage in Britain. Hampshire: Palgrave Macmillan.

Xinhua (2014): Charm of "Cultural Lancang", http://www.yn.xinhuanet.com/puer/201403/27/c 133217966.htm.

Xinhua (2017): Yunnan Publishes Fourth Provincial Level ICH Representatives Items Projects, http://news.xinhuanet.com/gongyi/2017-06/09/c 129629426.htm.

Yang, Li; Geoffrey Wall and Stephen L.J. Smith (2008): Ethnic tourism development: Chinese Government Perspectives, Annals of Tourism Research, 35 (3), 751-771.

YBC (2014): The Situation of Yunnan Province's Ethnic Traditional Cultural Environmental Protection, http://www.ynich.cn/book-view-51.html.

YNCD (Yunnan Province Culture Department) (2005): Notice on Implementing the Opinion of the Yunnan Province People's Government Office on Distributing and Carrying out the State Council Document on Strengthening National ICH Protection Work, http://www.cnnsr.com.cn/csfg/html/20051206000000105299.html.

You, Ziying (2015): Shifting Actors and Power Relations: Contentious Local Responses to the Safeguarding of Intangible Cultural Heritage in Contemporary China. In: Michael Dylan Foster and Lisa Gilman (eds.): UNESCO on the Ground. Local Perspectives on Intangible Cultural Heritage. Indiana University Press, 113-130.

Yu, Hua (2015): A vernacular way of "safeguarding" intangible heritage: the fall and rise of rituals in Gouliang Miao village, International Journal of Heritage Studies, 21 (10), 1016-1035. 
Yunnan gov. (Yunnan Provincial Government) (2005): Yunnan People's Government's Opinion on Advancing the Development of the Tea Industry, http://law1.lawstar.com/law?fn=lar444s769.txt.

Yunnan gov. (Yunnan Provincial Government) (2015): Pu'er Tea Origin Cultural Park, http://pelc.yninvest.gov.cn/InvestDetail.aspx?id=3374.

Yunnan Network (2016): Lancang County Lahu Minority's Bai Dance is to be classified in the 2014-2016 year of China's Folk Culture Art Villages, http://www.yunxunw.com/bianjiangwenhua/2016/0624/243.html.

Zhang, Jinghong (2014): Puer Tea. Ancient Canvas and Urban Chic. Seattle, London: Washington University Press.

Zhong, Yang (2003): Local Government and Politics in China. Challenges from Below (M.E. Sharpe Paperback). London, New York: Routledge.

Zhu, Yujie and Na Li (2013): "Groping for Stones to Cross the River: Governing Heritage in Emei", in Tami Blumenfield and Helaine Silverman, Cultural Heritage Politics in China, New York: Springer, pp 51-71.

Zhu, Yujie. 2016. 'Heritage making of Lijiang: Governance, reconstruction and local Naxi life', in Christoph Brumann and David Berliner eds. World Heritage on the Ground. Ethnographic Perspectives. Oxford: Berghahn, 78-96. 